\title{
Las entidades de economía social como protagonistas de un nuevo modelo de emprendimiento y medidas legales de apoyo al emprendimiento
}

\section{Luis Ángel Sánchez Pachón y Emilio Pérez Chinarro}

\section{RESUMEN}

El emprendimiento y los emprendedores son conceptos de moda en España. Los Gobiernos y las distintas Administraciones públicas promueven iniciativas que buscan el impulso, el reconocimiento o el apoyo a los emprendedores. Con este trabajo buscamos clarificar la situación del emprendimiento en España y, en particular, del emprendimiento social. Distinguimos los modelos de emprendimiento empresarial y de emprendimiento social, que protagonizan las empresas sociales y las entidades de economía social, con características diferentes a las empresas mercantiles tradicionales. Analizamos, con sentido crítico, el impacto, consecuencias y oportunidades que las reformas legislativas (nacionales y también algunas autonómicas) ofrecen en el apoyo o en el estímulo a los emprendedores, así como sus repercusiones en las entidades de economía social, principales artífices del emprendimiento social.

PALABRAS CLAVE: Emprendimiento, emprendedor, emprendimiento social, orientación emprendedora, entidad de economía social, empresa social.

CLAVES ECONLIT: L260, M130, M190, P130.

Cómo citar este artículo: SÁNCHEZ, L.A. \& PÉREZ, E. (2015): "Las entidades de economía social como protagonistas de un nuevo modelo de emprendimiento y medidas legales de apoyo al emprendimiento", CIRIEC-España, Revista de Economía Pública, Social y Cooperativa, 84, 35-62.

Correspondencia: Luis Ángel Sánchez Pachón, Profesor Contratado Doctor de Derecho Mercantil; Emilio Pérez Chinarro, Profesor Ayudante Doctor de Economía Aplicada. Universidad de Valladolid, Facultad de Ciencias Económicas y Empresariales, Avda. Valle Esgueva, 6. 47011-Valladolid. Emails: pachon@eco.uva.es, emilio@eco.uva.es 


\section{Les entités d'économie sociale en tant que protagonistes d'un nouveau modèle d'entrepreneuriat et mesures légales de soutien à l'entrepreneuriat}

RÉSUMÉ : L'entrepreneuriat et les entrepreneurs sont des concepts d'actualité en Espagne. Les gouvernements des différentes administrations publiques favorisent des initiatives cherchant à promouvoir, reconnaître et soutenir ces derniers. Avec ce travail, nous tentons de clarifier la situation de l'entrepreneuriat en Espagne, en particulier de l'entrepreneuriat social. Nous distinguons les modèles d'entrepreneuriat professionnel et social mis en place par les entreprises sociales et les entités de l'économie sociale, avec des caractéristiques différentes de celles des entreprises commerciales traditionnelles. Nous analysons, de manière critique, l'impact, les conséquences et les opportunités que les réformes législatives (nationales et parfois régionales) ont concernant le soutien ou la stimulation des entrepreneurs, ainsi que leurs répercussions sur les entités de l'économie sociale, artisans principaux de l'entrepreneuriat social.

MOTS CLÉ : Entrepreneuriat, entrepreneur, entrepreneuriat social, orientation entrepreneuriale, entité de l'économie sociale, entreprise sociale.

\section{Social economy entities as protagonists of a new model of entrepreneurship and legal measures to support entrepreneurship}

ABSTRACT: Entrepreneurship and entrepreneurs are fashionable concepts in Spain. Governments and various public authorities promote initiatives that seek to boost, recognise or support entrepreneurs. This paper seeks to clarify the situation of entrepreneurship in Spain, particularly social entrepreneurship. It distinguishes between models of entrepreneurship and social entrepreneurship, led by social enterprises and social economy organisations, which have different characteristics to traditional business enterprises. It undertakes a critical analysis of the impact, consequences and opportunities afforded by legislative reforms (national and some regional) in supporting or stimulating entrepreneurs and the impact of these reforms on social economy entities, the principal architects of social entrepreneurship.

KEY WORDS: Entrepreneurship, entrepreneur, social entrepreneurship, entrepreneurial orientation, social economy entity, social enterprise. 


\section{1.- Introducción}

En el ámbito científico, social y político existe un amplio consenso en el reconocimiento del valor social añadido que aporta la economía social: cohesión social, empleo, generación y mantenimiento de tejido social y económico, desarrollo de la democracia, innovación social, desarrollo local, etc. La ley española, Ley 5/2011, de 29 de marzo, de Economía social, supuso un paso muy importante en el reconocimiento institucional de la economía social en nuestro país. Ese reconocimiento jurídico explícito de la economía social y de sus agentes, que se hace en la Ley de economía social, debería facilitar que lo que hoy se viene caracterizando como acciones emprendedoras se canalicen también bajo las formas jurídicas de las empresas y entidades de economía social que esa Ley reconoce: cooperativas, mutualidades, fundaciones, asociaciones que realicen actividad económica, sociedades laborales, empresas de inserción, centros especiales de empleo, cofradías de pescadores, sociedades agrarias de transformación, además de las entidades que respondan a los principios que, conforme a la misma Ley, caracterizan a las entidades de economía social.

Todo ello, quizá, nos permita configurar un modelo de emprendimiento distinto; un modelo de emprendimiento que podemos adjetivar como un modelo de emprendimiento social; protagonizado por entidades con características diferentes a las empresas mercantiles tradicionales, donde los fines sociales como la generación de empleo estable y de calidad, la inserción social, la conservación del medio ambiente, la sostenibilidad..., constituyan la prioridad.

Desde esta perspectiva y con este marco regulador de la economía social en el que han de desenvolverse -con su normativa específica también- cada una de las entidades que conforman el sector de la economía social, pretendemos analizar, con sentido crítico, el impacto, consecuencias y oportunidades que representan las últimas reformas legislativas -nacionales y también algunas autonómicasde apoyo o estímulo al emprendimiento y a la creación de empresas. Apoyo que puede resultar especialmente oportuno en unos momentos de crisis económica como los que largamente venimos padeciendo.

En ese análisis prestamos especial atención a la Ley 14/2013, de 27 de septiembre, de apoyo a los emprendedores y su internacionalización. Destacamos sus puntos básicos y, en particular, las reformas legislativas de apoyo al emprendimiento que esa Ley lleva a cabo. Aludimos también al papel legislativo desempeñado por la Comunidades Autónomas, analizando, en particular, el de la Comunidad de Castilla y León con la aprobación de la Ley 5/2013, de 19 de junio, de Estímulo a la creación de Empresas. 
En fin, en nuestras conclusiones destacamos cómo esas reformas legislativas (estatal y autonómicas) dirigidas al apoyo del emprendimiento inciden en algunos factores de la potenciación de la iniciativa emprendedora: la cultura, la educación y algunos trámites administrativos; sin embargo, no parece que presten la atención necesaria a uno de los factores que sigue siendo clave para el emprendimiento, como es el de la adecuada financiación.

\section{2.- Emprendimiento y emprendimiento social: el emprendimiento a través de las entidades de economía social}

Como vienen a señalar los profesores Francisco Salinas Ramos y Lourdes Osorio Bayter, el emprendimiento es un término poliédrico que está directamente relacionado con la acción de la persona. En este sentido, vienen a definir estos autores el emprendimiento como el conjunto de actitudes y conductas que dan lugar a un determinado perfil personal orientado hacia la autoconfianza, la creatividad, la capacidad de innovación, el sentido de responsabilidad y el manejo del riesgo (Salinas y Osorio, 2012: 132). El emprendimiento, en términos generales, lleva implícito un dinamismo, una generación de ideas, una búsqueda de efectos beneficiosos sobre el conjunto de la economía y de la sociedad (Contreras y González, 2010: 143). De una u otra manera el emprendimiento supone una conducta creativa, una acción o conjunto de acciones creativas que, en función de las características que presenten 0 de quién 0 quiénes 0 cómo las realicen, nos permitirán calificar ese emprendimiento de una u otra manera.

En efecto, entre las distintas definiciones de emprendimiento, emprendedores, o iniciativas emprendedoras que la literatura cientíica -avalada, incluso, por los conceptos que se han manejado por algunas instituciones europeas- nos ha podido proporcionar, no suelen faltar las notas características que, de una u otra forma, redundan en la creación, en la innovación y, más en concreto, en la creación 0 desarrollo de una actividad económica. Y los rasgos caracterizadores, que con frecuencia configuran el emprendimiento, suelen ser la actitud y el impulso en la realización o desarrollo de una actividad económica; la creación de nuevas empresas; o la creación de una nueva organización o la reorganización de una organización existente.

Una tabla resumen de definiciones de iniciativa emprendedora la podemos ver en el Libro Blanco de la Iniciativa Emprendedora en España ${ }^{1}$. Ahí, además, se viene a señalar cómo la relevancia del emprendimiento, en la actualidad, se destaca por el papel que desempeña tanto en la generación de empleo como en el crecimiento económico y la innovación. De esta manera se propone una definición

1.- El Libro Blanco de la Iniciativa Emprendedora en España es un trabajo realizado por un equipo del Instituto de Iniciativa Emprendedora de ESADE. Vid. Alemany, L., Alvarez, C.; Planellas, M.; Urbano, D. (2011): Libro Blanco de la Iniciativa Emprendedora en España, Fundación Príncipe de Girona, Barcelona, p. 16. 


\section{LAS ENTIDADES DE ECONOMÍA SOCIAL COMO PROTAGONISTAS DE UN NUEVO MODELO DE EMPRENDIMIENTO Y MEDIDAS LEGALES DE APOYO AL EMPRENDIMIENTO}

de iniciativa emprendedora relacionada con una forma de pensar, razonar y actuar, vinculada y suscitada por la búsqueda de una oportunidad de negocio, el resultado de la cual es la creación, mejora, realización y renovación de valor en el sentido más amplio del término, es decir, no solo valor económico sino también social, y no solo para sus propietarios (los emprendedores o empresarios) sino, también, para todos los grupos de interés vinculados con ellos (empleados, clientes, proveedores y sociedad en general) (Alemany; Álvarez; Planellas, y Urbano, 2011: 31).

En este sentido, entendemos, quedan superadas, de alguna manera, las conceptualizaciones del emprendedor 0 de la iniciativa emprendedora que los identifican, simplemente, con el empresario o con la iniciativa empresarial. Idea que, sin embargo, no es extraña en un sector de la literatura jurídico-mercantil. Así, el profesor Juan Sánchez-Calero considera que el concepto de emprendedor no pasa de ser "un recurso lingüístico destinado a evitar hablar de empresarios como sujetos de alguna tutela". El término emprendedor -se viene a decir- es una forma "políticamente correcta" de hablar, en la modalidad elusiva. Y las medidas para los emprendedores serían, en realidad, una actualización de políticas de ayuda e impulso para las pequeñas y medianas empresas o para los autónomos. En definitiva, emprendedor y empresa o empresario vendrían a ser una misma cosa (Sánchez-Calero, 2012).

En la misma línea, Peinado Gracia y Roncero Sánchez vienen a considerar que si por emprendedor queremos referirnos a la persona que arriesga su capital y su esfuerzo para la creación de una empresa con la que actuar en el mercado, estaríamos hablando en términos generales de un empresario, y que si se prefiere el término emprendedor es porque llamarlo empresario parece antiguo y alude a un sujeto lleno de referencias peyorativas que van desde su ética a su estética (Peinado y Roncero, 2014: 1). Incluso, se ha llegado a decir que el término emprendedor es una "aberración gramatical" y no aporta nada nuevo resultando un término equivalente al de empresario (Enciso y Serrano, 2015: 4); o que "resulta innecesario", y que con la introducción de este nuevo concepto en nuestro sistema jurídico se corre el riesgo de crear confusión al agregarlo para referirse a un concepto tradicional que ya tenía un término previamente asignado y comúnmente conocido. Da la sensación -se concluye- que el legislador se ha dejado llevar, más que por la correcta técnica jurídica, por el marketing político, sustituyendo el término empresario por otro novedoso y con mejor imagen pública (Martos, 2015: 47).

Tampoco en las legislaciones encontramos siempre una idea de emprendedor o emprendimiento que supere $o$ se diferencie de la de simple empresario o de la de ejercicio profesional de una actividad económica. Dando la impresión, a veces, de una mera utilización oportunista, de un mero seguidismo de una terminología que está de moda en las últimos años.

Así, por ejemplo, se suelen considerar emprendedores a las personas físicas que se encuentren realizando trámites previos para poder desarrollar una actividad económica, bien sean como trabajadores autónomos, cooperativistas, socios de una pequeña y mediana empresa, sociedad laboral o a través de cualquier forma mercantil admitida en derecho. Posibilitándose también incluir dentro del concepto de emprendedor a "las sociedades mercantiles, trabajadores autónomos y otras formas societarias...", que cumplan determinados requisitos (Artículos 2 de la Ley 2/2012, de 14 de junio, DOCV, 
de 20 de junio de 2012 y BOE de 6 de julio de 2012, de Medidas Urgentes de Apoyo a la Iniciativa Empresarial y los Emprendedores, Microempresas y Pequeñas y Medianas Empresas de la Comunitat Valenciana). En la Comunidad autónoma de la Illes Balears, la Ley 2/2012, de 4 de abril (BOIB de 14 de abril y BOE de 2 de mayo de 2012) de apoyo a los emprendedores y las emprendedoras y a la micro, pequeña y mediana empresa, no diferencia significativamente a los emprendedores de los empresarios: los emprendedores son "las personas físicas o jurídicas que están iniciando o ya han iniciado, en un tiempo no superior a 2 años, una actividad económica en el territorio" (art. 2). En la misma línea la Ley 15/2011, de 15 de diciembre, de Emprendedores, Autónomos y PYMES, de Castilla-La Mancha (DOCM de 26 de diciembre de 2011 y BOE de 27 de marzo de 2012): "...se considerará emprendedor aquella persona física que se encuentre realizando los trámites previos para poder desarrollar una actividad económica, bien como trabajador autónomo, bien como pequeña o mediana empresa, a la que se incorpore como socio, y cuyo domicilio fiscal y actividad vaya a radicar en CastillaLa Mancha..." "Se entiende asimilado al concepto de emprendedor aquel que cumpliendo con la definición anterior lleve constituido o dado de alta en la seguridad social, según corresponda, menos de veinticuatro meses, siempre que no sea continuación o ampliación de una actividad anterior" (artículos 3 y 4). En Castilla y León son emprendedores, conforme a lo que se indica en el artículo 2 de la Ley 5/2013, de 19 de junio, de estímulo a la creación de empresas en Castilla y León (BOC y L de 3 de julio), "aquellas personas físicas o jurídicas que se encuentren realizando o vayan a realizar los trámites necesarios para poder desarrollar una actividad económica a través de cualquier forma admitida en derecho, 0 aquellas que hayan iniciado su actividad en los dos años siguientes a la fecha de la Declaración Censal de alta en el Censo de Empresarios, Profesionales y Retenedores y, en todo caso, que desarrollen o vayan a desarrollar su actividad en Castilla y León".

En parecidos términos, ligando el emprendimiento a la creación de empleo, se muestra la Ley del Parlamento vasco, aunque añade además que "son emprendedoras... aquellas personas que mantienen y desarrollan un compromiso ético permanente en su actuación, reflejado entre otros aspectos, en la vinculación al territorio y en el compromiso de mantenimiento de la actividad" (artículo 2 de la Ley 16/2012, de 28 de junio, BOPV de 6 de julio de 2012 y BOE de 19 de julio de 2012, de Apoyo a las Personas Emprendedoras y a la Pequeña Empresa del País Vasco).

En fin, la Ley 14/2013, de 27 de septiembre, de apoyo a los emprendedores y su internacionalización (BOE del 28), de la que después nos ocuparemos, considera emprendedores a "aquellas personas, independientemente de su condición de persona física o jurídica, que desarrollen una actividad económica empresarial o profesional, en los términos establecidos en esta Ley" (art. 3). Son emprendedores, pues, las personas, físicas o jurídicas ${ }^{2}$, cuando realizan una actividad económica cuya caracterización tendría que definirse en la Ley. El problema es que, a lo largo de la Ley, no se aprecian bien

2.- El Dictamen del Consejo Económico y Social sobre el Anteproyecto de lo que hoy es la Ley de apoyo a los emprendedores y su internacionalización, consideraba que en la definición de emprendedor debería constar claramente que, independientemente de la forma jurídica que adopte la empresa creada por el emprendedor, éste debería ser siempre una persona física. Vid. http://www.ces.es/documents/10180/631510/Dic062013.pdf?version=1.0 , p. 9. Vid., también, en este mismo sentido, la Enmienda núm. 4, a la totalidad del Proyecto de Ley de apoyo a los emprendedores y su internacionalización, presentada por el grupo el Grupo Parlamentario Mixto, BOCG de 26 de julio de 2013), donde se argumentaba que la inclusión de las personas jurídicas en el concepto de emprendedor "va en contra de la definición comúnmente aceptada referida solo a personas físicas". 


\section{LAS ENTIDADES DE ECONOMÍA SOCIAL COMO PROTAGONISTAS DE UN NUEVO MODELO DE EMPRENDIMIENTO Y MEDIDAS LEGALES DE APOYO AL EMPRENDIMIENTO}

cuáles son las normas destinadas a concretar los términos en los que ha de ejercerse la actividad empresarial o profesional para que quien la realiza pueda alcanzar la calificación de emprendedor. El Preámbulo de la Ley se refiere a la actividad económica productiva, lo que excluiría, por ejemplo, a las entidades de mera tenencia patrimonial, pero ese rasgo no aparece después en el articulado de la Ley3 ${ }^{3}$ Sólo el artículo 70 contiene una definición de actividad emprendedora y empresarial: se entenderá como actividad emprendedora aquella que sea de carácter innovador con especial interés económico para España y a tal efecto cuente con el informe favorable del órgano competente de la Administración General del Estado. Aquí no se hace referencia al concepto de actividad empresarial ni se establecen diferencias entre ésta y la actividad emprendedora, sin embargo, aparecen confundidas en otros preceptos (p. e. art. 68) y, en general, a lo largo de la Ley, se utilizan de manera indistinta los términos «actividad emprendedora», "proyecto empresarial», "actividad empresarial» y «actividad económica» como si fuesen intercambiables entre sí (Peinado y Roncero, 2014:1).

Sin embargo, desde el punto de vista teórico y según entendemos también nosotros, los conceptos de emprendedor y de iniciativa emprendedora, superan o difieren, de algún modo, de los conceptos de empresario o de iniciativa empresarial. Ni todos los empresarios son emprendedores, ni todos los emprendedores son ni tienen que terminar siendo empresarios. Esa diferenciación nos da pie, también, para abordar la idea de emprendimiento desde distintos campos o puntos de vista. Es cierto que en los últimos años la orientación emprendedora ha sido objeto de estudio, especialmente, en la literatura de la empresa y es cierto, también, que la mayoría de los trabajos se han centrado en el efecto de la orientación emprendedora en el desempeño empresarial (Hernández, 2014: 32-33). Sin embargo, esto no significa que esa orientación emprendedora no pueda ser abordada también, 0 además, desde otra perspectiva, donde se tengan en cuenta determinados objetivos o el papel de sus principales protagonistas.

Los profesores Salinas Ramos y Osorio Bayter, tomando las referencias de Moriano León, además de matizar que la acción emprendedora puede hacerse a título individual o formando parte de un grupo con o sin estructura, apuntan a que puede desarrollarse en diversos ámbitos, dando lugar a tres tipos de emprendimiento: el emprendimiento empresarial o emprendimiento de negocio, donde la principal motivación de sus acciones e iniciativas es de carácter económico-lucrativas; el emprendimiento social, que propone dar respuesta a necesidades sociales, promueve y sostiene valores, y sus conocimientos, capacidades y recursos los ponen al servicio de la sociedad, y el emprendimiento público, que es una iniciativa con motivación fundamentalmente política, donde se intenta trasladar la cultura de la empresa al sector público (Salinas y Osorio, 2012: 132).

La distinción, en nuestra opinión, es bastante esclarecedora y nos permite abordar el emprendimiento social como una variante del emprendimiento. Esta es, como nos recuerdan Marta Enciso Santocildes; Laura Gómez Urquijo y Aitziber Mugarra Elorriaga, la línea que siguen algunos autores y

3.- La disfunción entre el concepto del artículo 3 y el formulado en el Preámbulo, acotado al desempeño de actividades económicas productivas, no parece casual. Tanto en el Anteproyecto como en el Proyecto de ley, la definición de emprendedor estaba asociada a la realización de actividades económicas productivas. Durante la tramitación parlamentaria este último término se eliminó de la definición legal del artículo 3, sin embargo, quizá involuntariamente (Martos, 2015: 45), se mantiene en el Preámbulo. 
la mayor parte de las instituciones cuando se acercan al emprendimiento social desde el campo del emprendimiento (Enciso; Gómez y Mugarra, 2012: 63-64). Es cierto que un sector doctrinal prefiere configurar el emprendimiento social como una categoría aparte, independiente; lo que, como también recogen esos autores, no deja de influir en la diversidad de concepciones del emprendimiento social. Pero, en realidad, en esa configuración independiente del emprendimiento social, lo que hay es un intento de marcar distancias con los emprendedores empresariales o emprendedores de negocio.

En nuestra opinión, las preocupaciones o cautelas por marcar diferencias entre el emprendimiento empresarial o emprendimiento de negocio y el emprendimiento social, no tienen por qué desvincular el emprendimiento social del emprendimiento en términos generales. El emprendimiento social sigue siendo emprendimiento, aunque, evidentemente, tenga una caracterización propia que le diferencie del emprendimiento empresarial o emprendimiento de negocio. El emprendedor social "es un tipo de emprendedor que identifica una oportunidad de negocio que está basada en la resolución de un problema social... a través de una solución innovadora y creativa, apoyada en una buena idea y en el desarrollo de un proyecto empresarial". La principal diferencia entre un emprendedor de negocios y un emprendedor social -como señalan Contreras Comeche y González García- es que el objetivo del primero es el beneficio económico, mientras que el emprendedor social tiene por motivación el cambio social (Contreras y González, 2010: 5). Como también viene a señalar Sanchis Palacio, el emprendimiento social se desarrolla en un contexto en el que la persona y el trabajo son lo principal y el beneficio empresarial no es más que el resultado del trabajo bien hecho. A diferencia de otros tipos de emprendimientos, el emprendimiento social no tiene como objetivo la maximización del beneficio económico, sino que éste no es más que el instrumento o el medio que garantiza los fines sociales de las empresas que se constituyen bajo esta perspectiva. La persona y el grupo, además de ser el motor de la empresa, son también la principal prioridad, de manera que se trata de organizaciones socialmente responsables, tanto interna (hacia sus empleados) como externamente (hacia la sociedad en su conjunto) (Sanchis, 2010: 5). En definitiva, como se ha dicho, la clave de los emprendedores sociales se centra en la creación de valor social sostenible (Priede; López-Cózar y Rodríguez, 2014: 7-8). Y ese emprendimiento social puede realizarse a través de cualquier modelo de negocio. Es más, podríamos decir nosotros, puede realizarse a través de cualquier forma jurídica organizativa. De esta manera encuentra cabida en el emprendimiento social un nuevo concepto de empresa: la empresa social, que regida por criterios empresariales, habrá de orientar su negocio a unos objetivos sociales. El predominio de la "creación de valor social", se suele decir, es la característica básica de la empresa social (Burillo y Navarro, 2014: 72).

Esta idea de la empresa social, y de la empresa social como protagonista también del emprendimiento, cobra también auge en los últimos tiempos en el ámbito de la Unión Europea. Así en la Resolución del Parlamento Europeo, de 20 de noviembre de 2012, sobre la Iniciativa en favor del emprendimiento social -Construir un ecosistema para promover las empresas sociales en el centro de la economía y la innovación sociales- la Comisión reconoce que los actores de la economía social y las empresas sociales son impulsores del crecimiento económico y de la innovación social, con potencial para crear empleos sostenibles y para favorecer la inclusión de grupos vulnerables en el mercado 


\section{LAS ENTIDADES DE ECONOMÍA SOCIAL COMO PROTAGONISTAS DE UN NUEVO MODELO DE EMPRENDIMIENTO Y MEDIDAS LEGALES DE APOYO AL EMPRENDIMIENTO}

laboral. Confirma que las empresas sociales pueden contribuir a la prestación de los servicios sociales, que son elementos fundamentales del Estado del bienestar y que, por tanto, ayudan a alcanzar los objetivos de la Unión Europea; que la mayoría de las empresas sociales favorecen la reforma de las políticas mediante la promoción de la buena gobernanza, en particular, implicando a los trabajadores, los clientes y las partes interesadas, apoyan el aprendizaje mutuo y la innovación social, y, por tanto, responden a la demanda creciente de los ciudadanos de un comportamiento empresarial ético, social y respetuoso con el medio ambiente. En fin, que las empresas sociales, debido a su naturaleza y su modus operandi, contribuyen al establecimiento de una sociedad más cohesionada, democrática y activa, y a menudo ofrecen (o deberían ofrecer) unas condiciones laborales favorables, así como el mismo salario por el mismo trabajo, y respaldan la igualdad de oportunidades entre hombres y mujeres, permitiendo así la conciliación de la vida laboral y personal.

También, en Comunicación de la Comisión al Parlamento Europeo, al Consejo, al Comité Económico y Social Europeo y al Comité de las Regiones, de 25 de octubre de 2011, se viene a decir que la economía social agrupa a entidades con un régimen jurídico específico (cooperativas, fundaciones, asociaciones y mutuas), y que muchas de ellas son también empresas sociales, según las características mencionadas, y empresas sociales en forma de sociedad privada o de sociedad anónima tradicional. Añadiéndose que los regímenes jurídicos específicos de la economía social están especialmente adaptados a las empresas sociales, ya que su modo de gobernanza favorece la participación y la apertura.

Con todos estos datos podemos concluir que hay un tipo de emprendimiento que puede diferenciarse del emprendimiento empresarial o emprendimiento de negocio; un emprendimiento social, que propone dar respuesta a necesidades sociales, promueve y sostiene valores sociales; que pone sus conocimientos, capacidades y recursos al servicio de la sociedad. Un emprendimiento que se traduce en la creación o desarrollo de empresas en las que los fines sociales son la prioridad: la generación de empleo estable y de calidad, la inserción social por el trabajo o la conservación del medio ambiente y la sostenibilidad (Sanchis, 2010: 5). Un emprendimiento que, incluso, puede mostrarse como una alternativa para enfrentarse al problema del desempleo y evitar las tensiones sociales que pueden provocar otro tipo de medidas, como las últimas flexibilizaciones en el mercado de trabajo (Campos, 2010: 19). Un emprendimiento donde, mediante la generación de ideas, inversión de recursos, esfuerzo, compromiso personal, se trate de buscar soluciones a problemas sociales como el acceso a la vivienda, la inclusión de grupos vulnerables, el acceso al empleo, la formación, la gestión de la dependencia, etc. (Priede; López-Cózar y Rodríguez, 2014: 7). Un emprendimiento cuyos protagonistas podrán ser las entidades de economía social y, en términos más amplios, las empresas sociales ${ }^{4}$.

4.- En España, debido al carácter social y a la forma de organización, con marcado carácter asociativo, de las empresas sociales, éstas se han venido identificando con las entidades que integran la economía social. Sin embargo, y aunque no contamos con un concepto definitivo de empresa social, los autores suelen concluir que las empresas sociales pueden revestir formas jurídicas propias de las sociedades de capital. No existe una fórmula organizacional única ni un solo tipo legal aplicable, siendo éste un aspecto secundario, posibilitándose un abanico de formas jurídicas que deben ser capaces de dar respuesta a las propias necesidades de la empresa social (Burillo y Navarro, 2014: 83). 
En este sentido, el reconocimiento legal que de las entidades de economía social se hace en la Ley española 5/2011, de 29 de marzo de Economía social, facilita, entendemos, que el emprendimiento social se canalice bajo las formas jurídicas de las entidades de economía social. En España, hasta el momento, el emprendimiento social y, en concreto, la figura del emprendedor social no está reconocida ni comprendida como lo está en otros países del ámbito europeo. La Ley de Economía social puede ser la herramienta jurídica que lo facilite -y lo reclame-. Su artículo 4 recoge los principios orientadores de las entidades de economía social. Su contenido ha sido objeto de detenido análisis en nuestra doctrina (Fajardo, 2012: 245 y ss.; Paniagua, 2011; Paz, 2012; Sánchez, 2009, 61 y ss.; 2010, 53 y ss.). El artículo 5 de esa misma Ley, aunque no lo haga de manera lo suficientemente clara, permite -pensamos- delimitar las entidades que forman parte de la economía social con arreglo a un triple criterio:

- Entidades que tradicionalmente se vienen identificando como de economía social: cooperativas; mutualidades; fundaciones; asociaciones que lleven a cabo actividad económica; sociedades laborales; empresas de inserción; centros especiales de empleo (habrá que advertir, sin embargo, que algunas de ellas carecen de personalidad jurídica propia), a las que se añaden las cofradías de pescadores, y las sociedades agrarias de transformación. Tales entidades, en cualquier caso, se regularán por sus normas sustantivas específicas (art. 5.3).

- Entidades singulares creadas por normas específicas que respeten los principios orientadores recogidos en el artículo 4 de la Ley.

- Entidades que realicen actividad económica y empresarial y que, respetando los principios orientadores, se incluyan en el catálogo que al efecto llevará el Ministerio de Trabajo e Inmigración, previo informe del Consejo para el Fomento de la Economía Social y en coordinación con las Comunidades Autónomas, conforme al artículo 6 de la Ley.

Aunque en esa delimitación echemos de menos una conveniente vinculación de las entidades que se mencionan en el primer apartado con los principios rectores de la economía social -lo que evitaría los peligros que conlleva la atribución de la condición de entidad de economía social por la simple forma jurídica- no cabe duda que las formas jurídicas de las entidades de economía social previstas en la Ley pueden constituir un pertinente instrumental jurídico para el emprendimiento social. La crisis económica que venimos padeciendo, con sus más graves consecuencias para los sectores sociales más débiles, evidencia la necesidad del reconocimiento y apoyo institucional a las empresas y entidades que mayor empeño ponen en combatir la crisis y sus graves efectos en los sectores más desfavorecidos.

La organización -y en definitiva el éxito o los buenos resultados- de ese potencial reconocimiento 0 apoyo institucional pasa por tener presentes los factores más decisivos para el emprendimiento 0 para la iniciativa emprendedora y su situación en nuestra realidad económica. 


\section{3.- Factores clave para potenciar la iniciativa emprendedora y papel de las entidades de economía social en el emprendimiento}

El Libro Blanco de la Iniciativa Emprendedora, al que en otro momento nos hemos referido, describe detalladamente tres factores clave para potenciar la iniciativa emprendedora: la cultura, la educación y la financiación. Se dice también ahí que, inicialmente, se estudió el factor de los trámites administrativos, pero que, revisando la literatura y los resultados de las encuestas, se decidió dejar fuera, ya que no tenía el mismo peso que los otros tres y, además, se constataba que ningún emprendedor dejaría de serlo por tener más o menos trámites (Alemany; Álvarez; Planellas, y Urbano, 2011: 105 y ss.). El dato es significativo y, al menos, debería hacer reflexionar a los legisladores y gobiernos cuando estudian medidas que pretenden incentivar el emprendimiento. Los trámites administrativos no son un factor clave en el emprendimiento. En el informe de Agencia Estatal de Evaluación de las políticas públicas y la calidad de los servicios (AEVAL) sobre Trámites Administrativos para la creación de empresas en España, edición de 2008, se venía a concluir que para el $49 \%$ de los emprendedores los problemas financieros son más importantes que las trabas administrativas (40\%), como elementos disuasorios a la hora de constituir una empresa. Resulta también muy esclarecedora la Tabla que en el informe de AEVAL de 2012 recoge la clasificación de las fuentes citadas por los expertos como generadoras de obstáculos a la actividad emprendedora en España en 2011, donde el apoyo financiero, las políticas gubernamentales, las normas sociales y culturales, el clima económico figuran como los primeros obstáculos para la actividad emprendedora, mientras que "pese a la constante focalización de la problemática de las empresas en las trabas administrativas, la regulación tan solo representa la principal para el $2 \%$ de las empresas".

En ese mismo informe, al tratar de la influencia de los trámites administrativos en la decisión de emprender y en la creación de empresas y el peso o la relevancia de los trámites en la creación de empresas, se viene a decir que "debe ponderarse adecuadamente en qué grado la existencia de trámites administrativos puede representar un impedimento en la transformación de un proyecto emprendedor o empresarial, -que no deja de ser una intención-, en una empresa concreta... los trámites administrativos no tienen por qué ser la principal restricción o impedimento para crear empresas, sino que en la decisión de emprender figuran también, según todos los estudios consultados, y en meritorios primeros puestos, las facilidades o dificultades de financiación y la coyuntura general de la economía".

Por otra parte, como venía a reconocer aquél informe de 2008, no puede ignorarse que en la consideración de la tramitación administrativa, como un obstáculo o traba para la creación de empresas, se oculta una contradicción: por un lado la defensa de la libertad de empresa, y con ello el derecho a llevar a cabo actividades empresariales (artículo 38 de la Constitución Española), pero por otro, la obligación de los poderes públicos de proteger a sus ciudadanos y de garantizar también los derechos de 
carácter social, como corresponde al Estado social que se proclama en el mismo texto constitucional (artículo 1). Los poderes públicos no pueden hacer dejación de su función como garantes de esos derechos, aunque ello suponga una traba a la creación de empresas en cuanto aumente el número de trámites y controles y, con ello, el tiempo y los costes directos e indirectos. Evidentemente será necesario seguir trabajando en la búsqueda de la mayor simplificación, agilización, comodidad de la tramitación y pensando siempre en las personas; pero, en nuestra opinión, tampoco debería obsesionar la idea de la "reducción del tiempo para constituir empresas". Las reformas que se han hecho en ese sentido, con mucha frecuencia, han venido a revelar no solo su inutilidad sino sus peligros. La elaboración de un plan serio y riguroso de empresa -que, evidentemente, no se hace en unas horas, a pesar de lo que parecen pensar los legisladores y gobiernos con sus últimas reformas- evitaría muchas crisis y muchas disoluciones prematuras de empresas y, por tanto, muchos gastos, costes y perjuicios, no solo para los miembros y acreedores de esas entidades, sino para terceros y para la propia Administración pública.

Los tres factores clave para potenciar la iniciativa emprendedora, se concretan, pues, en la cultura, la educación y la financiación.

\section{a) Cultura}

Como se recoge en el Libro Blanco de la Iniciativa emprendedora, en la literatura sobre emprendimiento muchos autores se han centrado en las características de la personalidad de los emprendedores: necesidad de logro, independencia, control interno, propensión al riesgo, autoconfianza. Pero las características de la personalidad están interrelacionadas con la cultura de los grupos y de los colectivos, y no cabe duda que la cultura emprendedora de nuestros pueblos dista bastante de las culturas de grupos y sociedades de otros países tradicionalmente emprendedores. Las conductas y actividades del ser humano están condicionadas por la cultura, que indica lo que se considera deseable o no deseable en una sociedad. Las personas emprendedoras no son ajenas a la cultura en la que se desenvuelven; por lo que es de esperar que la motivación para emprender sea mayor si la actividad emprendedora está aceptada socialmente y la función emprendedora es valorada y admirada. Por el contrario, actitudes como el miedo al fracaso empresarial y la aversión al riesgo inhiben a potenciales emprendedores que desean poner en marcha una actividad económica.

Es claro que en España es necesario seguir avanzando en la cultura emprendedora entendida en ese sentido. En nuestro entorno, por ejemplo, el fracaso empresarial sigue apareciendo muy estigmatizado y, quizá, no se reconoce lo suficiente el valor del emprendedor como creador de riqueza, empleo, servicios a la sociedad. El apoyo institucional a la iniciativa emprendedora y el impulso a la educación y formación en las competencias necesarias de los emprendedores, contribuiría a ese avance. Porque a emprender también se aprende y los emprendedores también se hacen. 


\section{b) Formación}

En la actualidad hay un consenso bastante generalizado en que la iniciativa emprendedora constituye una disciplina, como cualquier otra, que puede aprenderse. En el Libro Blanco de la Iniciativa emprendedora, al que venimos refiriéndonos, se recoge cómo los expertos tienen una visión muy crítica sobre la formación en emprendimiento en España. La educación primaria y secundaria no ha tenido hasta ahora un plan para el fomento de actitudes emprendedoras y las Universidades, en general, tampoco vienen facilitando una formación para la iniciativa emprendedora. Ya en el informe de la Comisión Europea de 2008, elaborado a partir de los informes nacionales de los países entonces miembros, una de las conclusiones era que la enseñanza de la iniciativa emprendedora no estaba suficientemente incorporada en los planes de estudio de las instituciones de enseñanza superior.

No cabe duda que la educación puede contribuir enormemente a la creación de una cultura emprendedora, que debe empezar en la escuela y por los más jóvenes. Hasta ahora en la Enseñanza Secundaria la formación en emprendimiento quedaba reducida a una asignatura -"iniciativa emprendedora"- de carácter de optativa y de dos horas semanales.

Tampoco en la enseñanza superior los planes de estudio vienen ofreciendo especial preocupación por la formación en la iniciativa emprendedora, ni siquiera en los estudios específicamente empresariales. No obstante, en los últimos tiempos las Universidades parecen mostrar una mayor preocupación por el emprendimiento a través de jornadas, seminarios, talleres, premios, creación de Cátedras de emprendedores. Por el momento, sin embargo, estos estudios no tienen mucha repercusión en la enseñanza reglada. En abril de 2012 la Confederación Empresarial Española de la Economía Social (CEPES) y la Conferencia de Rectores de las Universidades Españolas (CRUE) firmaron, en la sede de la UNED en Madrid, un convenio para fomentar el espíritu emprendedor desde las fórmulas empresariales de la Economía Social en las actividades académicas habituales de las universidades españolas: estudios oficiales de grado y de postgrado, líneas de investigación y análisis, y generación de servicios de orientación y apoyo a los emprendedores universitarios. En ese ámbito de la enseñanza reglada pensamos que, en la actualidad, pude resultar de gran interés en la formación de la iniciativa emprendedora el aprendizaje que se adquiere a través de las prácticas de empresa. En este sentido, no debiera descuidarse su potenciación y seguimiento.

\section{c) Financiación}

El informe de AEVAL sobre Evaluación de las trabas administrativas para la creación de empresas, de 2012, que hemos mencionado, constata cómo la financiación aparece como el problema fundamental a la hora de poner en marcha una iniciativa emprendedora. También en Libro Blanco de la Iniciativa emprendedora en España se señala, que el capital es esencial para poner en marcha una empresa y que las limitaciones financieras tienden a excluir a aquellos que no disponen de fondos suficientes (Alemany; Álvarez; Planellas, y Urbano, 2011: 139 y ss.). En cualquier caso, el capital nece- 
sario estará relacionado con el proyecto de empresa que se pretenda y a cada etapa de desarrollo de una empresa le podrá convenir un tipo de financiación.

Además de las fuente de financiación comunes en el ámbito empresarial, se suelen señalar como fuentes principales de financiación para los emprendedores las siguientes: los préstamos bancarios, el capital riesgo (venture capital), los ángeles inversores (business angels) y fuentes alternativas, como pueden ser los distintos métodos que reducen los requerimientos de capital, mejorando el flujo de caja y aprovechando las fuentes personales de financiación; por ejemplo, a través del uso de tarjetas de crédito; retrasando el pago a los proveedores; retrasando el pago de impuestos, compartiendo el equipo o los empleados con otras empresas, utilizando sistemas de arrendamiento financiero como el leasing, etc.

De todas esas fuentes de financiación, en nuestra opinión, la que, quizá, más proyección e interés pudiera ofrecer, es la de los "ángeles inversores". Éstos son personas que invierten su propio dinero o sus conocimientos en proyectos con alto potencial de crecimiento, generalmente en fases muy tempranas de su desarrollo, a cambio de una participación en la empresa. También contribuyen con su experiencia y su red personal de contactos en la gestión empresarial. En algunos casos los business angels se asocian en clubs de inversión, a veces denominadas redes de business angels. La presencia de estas redes les facilita la actividad inversora a través de foros de inversión, en los que los emprendedores que se encuentran buscando capital presentan sus proyectos a la red. Las posibilidades de estas redes son evidentes y, en nuestro ordenamiento jurídico, un instrumento jurídico que facilitaría la participación de los inversores en los proyectos empresariales puede ser las cuentas en participación, previstas en los artículos 239 a 243 de nuestro vigente Código de Comercio (contrato de participación lo llama lo que habrá de ser el nuevo Código Mercantil, conforme a los artículos 545.1 a 545.5 del Anteproyecto de Ley del Código Mercantil, presentado por los Ministerios de Justicia y de Economía y Competitividad el 30 de mayo de 2014).

\section{4.- Actuaciones en emprendimiento de la legislación nacional y perspectivas de las entidades de economía social}

El marco regulatorio e institucional en el que se desarrollan las actividades empresariales resulta de esencial importancia para impulsar la mejora de la productividad y el aprovechamiento de los recursos, por eso, como se ha venido a decir, resulta clave que desde las administraciones públicas se potencie y facilite la iniciativa emprendedora, especialmente en la coyuntura económica actual. En este sentido, el apoyo a la iniciativa emprendedora, al desarrollo empresarial y a la creación de empleo será la lógica común que vertebre los dos textos legales: Ley 11/2013, de 26 de julio y Ley 14/2013, de 27 de septiembre (Mateo, 2014: 322). El problema, sin embargo, es que, en nuestra opinión, no se 
ha hecho adecuadamente. Particularmente la Ley 14/2013 no puede librarse de justificadas críticas; críticas que no solo son de carácter técnico-jurídico. Se ha llegado a hablar de "bazofia" (Alfaro, 2013), ha sido objeto de frívolos comentarios. Se ha hablado de "zafarrancho de mercado"; de "menú de empresas mercantiles"; de "ocurrencias" del legislador (Cazorla, 2013; Enciso y Serrano, 2015: 6); se ha dicho que contempla curiosas "empresas de estudiantes"; "empresas de deudores"; "empresas de extranjeros"; se ha dicho que contiene "cursilerías"; "redundancias", "brindis al sol", (Chaves García, 2013), etc.

Por nuestra parte, sin entrar en todos esas cuestiones, algunas técnicas, otras de política jurídica -muchas de ellas sin duda criticables-, nos centramos en el resumen de las actuaciones de emprendimiento que pueden llegar a tener más repercusión en las empresas y, particularmente, en las entidades de economía social, en cuanto protagonistas del emprendimiento.

Tomamos para ello, y ciñéndonos ahora al ámbito nacional, como referencia la Ley 11/2013, de 26 de julio, de medidas de apoyo al emprendedor y de estímulo del crecimiento y de la creación de empleo y, particularmente, la Ley 14/2013, de 27 de septiembre, de apoyo a los emprendedores y su internacionalización.

La Ley 11/2913 proviene del Real Decreto-Ley 4/2013, de 22 de febrero, del mismo nombre, que fue tramitado como proyecto de Ley, trasponiendo, sin cambios sustanciales, su contenido. La ley contiene diversas actuaciones en materia laboral y de seguridad social así como de fomento a la financiación empresarial, de financiación para el pago de proveedores de las entidades locales y comunidades autónomas y de lucha contra la morosidad en las operaciones comerciales.

Entre las medidas de estímulo a la contratación, en el artículo 14, bajo el rótulo de incentivos a la incorporación de jóvenes en entidades de economía social, únicamente se contemplan una serie de bonificaciones en las cuotas empresariales de la Seguridad Social, aplicables a cooperativas o sociedades laborales que incorporen trabajadores desempleados menores de 30 años (art. 14.1 a), así como la aplicación del Programa de Fomento de Empleo, previsto en la Sección Primera del capítulo I de la Ley 43/2006, de 29 de diciembre, sin la interesante excepción de su artículo 6.2 (art. 14.2, párrafo I). Asimismo, se recogen bonificaciones en las cuotas de la Seguridad Social aplicables a las empresas de inserción en contratos suscritos con menores de 30 años en situación de exclusión social (art. 14.1 b), sin perjuicio, también, de lo establecido en la Sección Primera del capítulo I de la Ley 43/2006, de 29 de diciembre (art. 14.2, párrafo II).

Sin duda tiene mucha más importancia la Ley 14/2013, de 27 de septiembre, de apoyo a los emprendedores y su internacionalización. Se trata de una Ley que había sido comprometida por el Gobierno desde hacía tiempo, lo que había generado unas expectativas que, en muchos casos, sin embargo, el texto final ha visto frustradas. Su artículo 1 señala el objeto de la Ley, que puede enmarcarse en las iniciativas tendentes a reactivar la economía, potenciar la creación de empleo, fortalecer el tejido empresarial de forma duradera, fomentar la cultura emprendedora. 
No es nuestro objetivo realizar una exégesis de todos los aspectos novedosos que ofrece la Ley; buscamos únicamente resaltar aquellos que puedan tener una incidencia en el emprendimiento social y en sus protagonistas 0 aquellos que reconozcan una especial consideración con el emprendimiento social. Adelantamos que no hay una especial consideración con este emprendimiento, lo que contrasta con otras normas autonómicas, como después apuntaremos.

El artículo 3 de la Ley contiene una definición de emprendedor que, como ya anticipamos, termina identificándolo con el empresario 0 el profesional. Para la Ley son emprendedores los empresarios, sean personas físicas o naturales 0 sean personas jurídicas o morales y, también, los profesionales; es decir, los profesionales liberales, que tradicionalmente se les ha excluido de la consideración empresarial pero que cada vez en más circunstancias quedan sujetos a lo que conocemos como estatuto jurídico del empresario.

En este sentido, aunque en la definición de emprendedor se incluya también a los profesionales liberales, la definición no deja de ser pobre o incompleta y, como tuvimos ocasión de apuntar al comienzo, una definición que no se corresponde con los conceptos de emprendedor y de emprendimiento que suele manejar la doctrina especializada. En esas definiciones o conceptos teóricos no suelen faltar, según vimos, unos rasgos caracterizadores: la actitud o el proceso de creación o desarrollo de una actividad económica; la idea, la creación, la mejora o la renovación de organizaciones para un mayor valor. Un valor, además, en un sentido amplio del término, es decir, no solo valor económico sino también social, y no solo para sus propietarios o titulares (los emprendedores o empresarios) sino también para todos los grupos de interés vinculados con ellos (empleados, clientes, proveedores y sociedad en general).

Después de definir, en la forma que lo hace, a los emprendedores, el legislador, consciente también de la importancia de la formación como uno de los factores claves del emprendimiento, dedica el Capítulo I del Título I a la "educación en emprendimiento" (artículos 4 a 6). Las medidas adoptadas y los objetivos que se persiguen se han considerado loables, aunque se augura su difícil aplicación, particularmente en el ámbito Universitario (Enciso y Serrano, 2015: 4). Además, en la Disposición adicional novena contempla la, más que curiosa, miniempresa o empresa de estudiantes. Es una herramienta puramente pedagógica y, en nuestra opinión, probablemente inoperante. Deberá inscribirse en un registro que se habilitará al efecto, lo que permitirá a la miniempresa realizar transacciones económicas y monetarias, emitir facturas y abrir cuentas bancarias. La miniempresa 0 empresa de estudiantes tendrá una duración limitada a un curso escolar prorrogable a un máximo de dos cursos escolares.

El Capítulo II del Título I regula lo que llama "Emprendedor de responsabilidad limitada". Aunque el nombre puede dar lugar a confusión, no se trata más que de un empresario -o profesional liberalindividual, al que, en determinadas circunstancias y con determinadas condiciones y obligaciones, se le concede una limitación de responsabilidad por deudas empresariales o profesionales, que únicamente afecta a la vivienda habitual siempre que su valor no supere los $300.000 €(300.000 \times 1.5$, en 
poblaciones de más de un millón de habitantes). La inutilidad de la figura -ya existe una figura más segura como es la sociedad unipersonal (Mateo, 2014: 331), las obligaciones que acarrea y los interrogantes que plantea, pueden explicar el poco atractivo que en la práctica muestra esta figura. De hecho, esta realidad se confirma con los datos estadísticos: de septiembre de 2013 a marzo de 2014 solo 25 autónomos se habían acogido a esta figura (Enciso y Serrano, 2015: 6).

El Capítulo III del Título I introduce una especie de sociedad limitada de formación sucesiva, que no es más que posibilitar una Sociedad de Responsabilidad Limitada con cifra de capital inferior a la mínima legal (3.000 €), estableciéndose unos límites y condiciones; como destinar a reserva legal al menos el 20\% del beneficio; no repartir beneficios hasta que el patrimonio no supere el $60 \%$ del capital mínimo; retribuciones a socios y administradores inferiores al $20 \%$ del patrimonio; en caso de liquidación, responsabilidad solidaria de socios y administradores hasta $3.000 €$. Todo ello, lógicamente, ha conllevado las consiguientes modificaciones de la Ley de Sociedades de Capital. Si el objetivo con esta reforma era -como reza el Título I- el "Apoyo a la iniciativa emprendedora", se puede comprender fácilmente que se hable del "desastre" de la Sociedad de Responsabilidad Limitada de Formación Sucesiva (Cazorla, 2013), como forma de cualquier tipo de emprendimiento. La figura supone demasiadas trabas para unos beneficios tan escasos (Enciso y Serrano, 2015: 6).

El Capítulo IV del Título I lo dedica la Ley a facilitar la tramitación administrativa para el inicio de la actividad emprendedora. Cosa distinta es que lo consiga. Una vez más se muestra la obsesión por eliminar o agilizar trámites en la constitución de las empresas, cuando, como anticipamos, lo que conocemos como trámites administrativos, no son un factor fundamental para el desarrollo de la iniciativa emprendedora. Desde luego serán bien venidos los nuevos PAE (Puntos de Atención al Emprendedor que sustituyen a los PAIT), pudiendo ser de carácter público o privado. Será bien recibida la posibilidad de realizar trámites telemáticamente (declaración censal; alta en Seguridad Social; solicitud de licencias; legalización de libros etc.). Como lo serán, también, otras simplificaciones de tramitaciones y cargas administrativas que se hacen en la Ley (artículos 22, 36-41 y 48-49). Lo que parece menos recomendable, en nuestra opinión, es, por ejemplo, la invitación a la constitución exprés de sociedades (entre 6 y 12 horas) o a la utilización de estatutos tipo en formato estandarizado; cuestiones que poco tienen que ver con una auténtica y fiable iniciativa emprendedora y que, a veces, generan más problemas y costes para todos que una iniciativa emprendedora que se asiente en un pensado y recomendable plan de empresa. Probablemente, la única ventaja de esas medidas legales sea -si es que realmente lo es- el hecho de que nuestro país escale posiciones en los indicadores relativos a la facilidad para la apertura de un negocio o inicio de una actividad empresarial en el informe Doing Business, que se publica por el Banco Mundial, como, al parecer, ha ocurrido (Enciso y Serrano, 2015: 8).

Por otra parte, la regulación del inicio de la actividad propuesta por la Ley, a veces, ralentiza más que agiliza. Prueba de ello son los conflictos que está generando la "sectorización universal de la actividad de los emprendedores", prevista en el artículo 20. En este sentido, pueden verse las Resoluciones de la Dirección General de Registros y del Notariado de 2, 3 y 4, de junio de 2014 (BOE de 25 de 
julio de 2014). Lo que no deja de poner en evidencia cómo, a veces y lamentablemente, las estadísticas del emprendimiento preocupan más a los Gobiernos y Administraciones que la realidad que las ha de fundamentar.

El Capítulo V del Título I, bajo el rótulo de Acuerdo Extrajudicial de pagos, introduce diversas modificaciones de la Ley Concursal, Ley 22/2003, de 9 de julio, (más adelante también se modifica esta Ley para introducir un nuevo artículo 71 bis sobre acuerdos de refinanciación). En el Preámbulo de la Ley 14/2013 se busca justificar este mecanismo de negociación extrajudicial de deudas de los empresarios, sean personas físicas o jurídicas, en que en la situación económica actual- según se dice- son necesarios tanto cambios en la cultura empresarial como normativos, al objeto de garantizar que el fracaso no cause un empobrecimiento y una frustración tales que inhiban al empresario de comenzar un nuevo proyecto y pase a ser un medio para aprender y progresar. Sin embargo, si se analizan las modificaciones introducidas (por ejemplo los artículos 235 y ss. de la Ley Concursal), parece que se está pensando más en los acreedores -o en algunos de los acreedores- que en el apoyo a emprendedores que fracasan en los primeros intentos.

El Título II de la Ley14/2013, con el rótulo de Apoyos fiscales y en materia de seguridad social a los emprendedores, contiene algunas modificaciones impositivas, a las que habría que sumar las que se realizan en la Disposición Final octava, que modifica la Ley 11/2013, de 26 de julio. Así, se introduce el llamado "régimen especial del criterio de caja" en el IVA, que supone que el impuesto -opcionalmente- se devengue en el momento del cobro total o parcial del precio por el importe efectivamente percibido. En la práctica -quizá por sus restricciones- no ha tenido el éxito esperado. De todos los trabajadores por cuenta propia y pequeñas y medianas empresas que podían acogerse al sistema, a fecha de abril de 2014, no llegaban al 1\% (Enciso y Serrano, 2015: 8). En el Impuesto de sociedades, se establecen medidas para fomentar la capitalización empresarial (deducción por inversiones; I+D+i; reducción de rentas de activos intangibles; creación de empleo de discapacitados). En el Impuesto sobre la Renta de las Personas Físicas, se incentiva a los business angels (deducción por Inversiones en empresas nuevas; exención por reinversión).

El apoyo en materia de Seguridad Social se concreta en algunas ventajas en la cotización de autónomos en pluriactividad; reducciones de cotización para las altas en autónomos de 30 o más años de edad; reducciones en las altas de autónomos discapacitados (medida esta que, junto a la anterior, se aplica también a los socios de trabajadores de cooperativas de trabajo asociado encuadradas en el Régimen Especial de la Seguridad Social de Trabajadores por Cuenta Propia o Autónomos); nuevas condiciones de embargo de vivienda del Autónomo por deudas de Seguridad Social.

El Capítulo II del Título IV, se rotula Medidas para impulsar la contratación pública con emprendedores. En realidad se trata de algunas modificaciones a diversos artículos de la Ley de Contratos del Sector Público, que afectan al acceso de los empresarios -algunas lo facilitan y otras lo restringen o lo fiscalizan- a la contratación pública. Se facilitan las formalidades de las uniones de empresarios (UTEs); se elevan los umbrales económicos de los contratos para las exigencias de clasificación de 
los empresarios (art. 43); se facilita la constitución de alguna garantía para la contratación pública (art. 44); se reducen los plazos de devolución o cancelación de las garantías para las PYMEs (art. 46); se reduce el plazo de demora en el pago de la Administración para poder resolver el contrato y se añade la posibilidad de controles por las Administraciones de pagos de los contratistas a subcontratistas y suministradores (art. 47).

En este ámbito de la contratación pública el artículo 45 recoge, además, la prohibición de discriminación a favor de contratistas previos en los procedimientos de contratación pública. De tal manera que no se podrá otorgar ninguna ventaja directa o indirecta a las empresas que hayan contratado previamente con cualquier Administración, y serán nulas de pleno derecho todas aquellas disposiciones contenidas en disposiciones normativas con o sin fuerza de Ley así como en actos o resoluciones emanadas de cualquier órgano del sector público que otorguen, de forma directa o indirecta, ventajas a las empresas que hayan contratado previamente con cualquier Administración. Se trata, más bien, de una medida propia del Derecho de la competencia, en nuestra opinión muy discutible y que, en realidad, frustra cualquier expectativa de ventajas que legítimamente -pensamos nosotros- pudieran albergar en los procedimientos de contratación públicas algunas entidades o promotores de economía social; particularmente pensamos en los Centros Especiales de Empleo y en las Empresas de Inserción.

El Título V de la Ley se dedica a la internacionalización de la economía española. La sección $1^{a}$ al fomento de la internacionalización, reforzando el marco institucional y algunos de los instrumentos financieros (artículos 50-60). La estrategia de fomento de la internacionalización se ha de plasmar en un Plan Estratégico de Internacionalización de la Economía Española. El correspondiente a 20142015 fue aprobado por el Consejo de Ministros, a propuesta del Ministerio de Economía y Competitividad, el 28 de febrero de 2014.

La Sección $2^{a}$ del Título V, con el rótulo de Movilidad Internacional, facilita y agiliza las concesiones y autorizaciones de residencia a determinados extranjeros de fuera de la Unión Europea: inversores; emprendedores; profesionales altamente cualificados; investigadores; trabajadores que efectúen movimientos intraempresariales dentro de la misma empresa o grupo de empresas y, en su caso, a los cónyuges e hijos mayores. El objetivo, más que el apoyo al emprendimiento y a los emprendedores, es, claramente, atraer inversión del exterior. Objetivo que, por lo demás, parece que ha tenido buenos resultados (Enciso y Serrano, 2015: 10). Otro modo de inversión exterior se contempla en el artículo 34, que regula la captación de financiación -por bancos, cajas, Instituto de Crédito Oficial, establecimientos financieros de crédito, incluidas, también, las cooperativas de crédito- posibilitando la emisión de cédulas y bonos de internacionalización y que ha tenido su desarrollo en el Real Decreto 579/2014, de 4 de julio (BOE del 16) por el que se desarrollan determinados aspectos de la Ley 14/2013, de 27 de septiembre. Todas estas medidas facilitadoras de la inversión extrajera contrastan con los límites y condiciones que las normas de extranjería prevén para la entrada y permanencia de otros emigrantes en nuestro país. 


\section{5.- Actuaciones en la legislación autonómica: la Ley de Castilla y León, 5/2013, de 19 de junio, de estímulo a la creación de empresas}

Ante la crisis económica y financiera que venimos padeciendo también las instituciones públicas del ámbito autonómico han propiciado distintas actuaciones orientadas al desarrollo del fenómeno del emprendimiento. Todas las Comunidades Autónomas cuentan con algún sistema de servicio público de apoyo 0, al menos, de información y asesoramiento a los emprendedores. No hace mucho la Confederación Empresarial Española de Economía Social (CEPES), publicó el documento "Servicios Públicos Autonómicos de Apoyo a los Emprendedores" (27 de marzo de 2014), que agrupa los servicios, herramientas, portales web y otros recursos públicos existentes en cada Comunidad autónoma para el apoyo al emprendedor ${ }^{5}$. En el ámbito normativo también las instituciones autonómicas han venido elaborando distintas disposiciones, algunas, incluso, con rango de ley: Castilla-La Mancha: Ley 15/2011, de 15 de diciembre; Illes Balears, Ley 2/2012, de 4 de abril; Valencia: Ley 2/2012, de 14 de junio; País Vasco: Ley 16/2012, de 28 de junio; Navarra: Ley Foral 12/2013, de 12 de marzo; Murcia: Ley 5/2013, de 8 de julio; La Rioja: Ley 10/2013, de 21 de octubre; Galicia: Ley 9/2013, de 19 de diciembre.

De todas ellas queremos fijarnos ahora en la de Castilla y León; en concreto, en la Ley 5/2013, de 19 de junio, de Estímulo a la creación de empresas en Castilla y León (BOCyL de 3 de julio de 2013; BOE de 15 de julio de 2013). Sus puntos básicos, a los que después nos referiremos, se nos presentan -pensamos- como un ejemplo bastante ilustrativo de la situación normativa del emprendimiento social en el ámbito autonómico de nuestro país.

La Ley Castellana y Leonesa es una Ley bien estructurada y hay que reconocer su buena construcción técnico-jurídica. A la hora de establecer los destinatarios de la norma tiene, además, el mérito de reconocer una especial consideración, por su incidencia en la creación de empleo, a los autónomos, las pequeñas y medianas empresas, las empresas familiares y las de economía social" (art. 2.3). Y en su artículo 22, a la hora de concretar las medidas de apoyo a la financiación pública y privada, se vuelve a mencionar, expresamente también, a las empresas de economía social ${ }^{6}$.

Sin embargo, no dejan de sorprender algunos olvidos -probablemente inconscientes pero no excusables- que, aunque sean en la Exposición de motivos y, por ello, carezcan de efectos jurídicos, reflejan el camino que aun nos falta por hacer en el convencimiento de la necesidad del reconocimiento

5.- Vid. CEPES (2014): "Servicios públicos autonómicos de apoyo a los emprendedores", 27 de marzo de 2014, http://www.observatorioeconomiasocial.es/media/archivos2012/Servicios_autonomicos_apoyo_emprendedores.pdf.

6. - Su artículo 22, bajo el enunciado de Medidas de apoyo a la financiación pública y privada, dispone:

La Administración de la Comunidad de Castilla y León podrá desarrollar las medidas siguientes de impulso de la financiación pública y privada de los proyectos empresariales, con una atención especial a las nuevas empresas que surjan en el ámbito rural y a las de economía social y de autónomos... 


\section{LAS ENTIDADES DE ECONOMÍA SOCIAL COMO PROTAGONISTAS DE UN NUEVO MODELO DE EMPRENDIMIENTO Y MEDIDAS LEGALES DE APOYO AL EMPRENDIMIENTO}

de la economía social y de sus valores. En el apartado II, párrafo segundo, de esa Exposición de motivos se alude al artículo 16 del Estatuto de Autonomía de Castilla y León. Ese artículo recoge los principios rectores que deben orientar las políticas públicas y las medidas necesarias para garantizar los objetivos que se mencionan. En la Exposición de motivos de la Ley se reproduce, incluso, el contenido del número 5 del artículo 16 del Estatuto, pero se omite -imperdonablemente- la referencia a las iniciativas de la economía social y al cooperativismo que expresamente el artículo 16.5 del Estatuto recoge como uno de los principios rectores de las políticas públicas?

Pero más imperdonable resulta que en el I Plan de Apoyo a la Creación de Empresas, aprobado por el Consejo de Gobierno de la Junta de Castilla y León (Acuerdo 34/2014, de 10 de abril, de la Junta de Castilla y León, BOCyL del 14, por el que se aprueba el I Plan de Apoyo a la Creación de Empresas en Castilla y León), en cumplimiento de lo dispuesto en el artículo 24.2 de la Ley 5/2013, se haya vuelto a incurrir en la misma omisión cuando se reproduce, en página 25745 del BOCyL, el artículo 16.5 del Estatuto de Autonomía de Castilla y León.

Con todo, la Ley 5/2013, de 19 de junio, nos ofrece una buena ordenación de medidas de apoyo a la iniciativa emprendedora. Resumidamente, como puntos básicos de la misma, destacamos los siguientes:

\section{a) Sensibilizar y promover la creación y consolidación del espíritu emprendedor (Título II)}

En el Título II se recogen actuaciones en el sistema educativo universitario y no universitario y fuera de los centros educativos; en relación al sistema educativo no universitario se dictó la Resolución de la Dirección General de Política Educativa Escolar (Consejería de Educación) de 30 de agosto de 2013. Además, centrándonos en el ámbito que nos ocupa, es de resaltar el compromiso que se impone a la Administración en el artículo 7. Ahí, expresamente, se encomienda a la Administración de la Comunidad el fomento de la responsabilidad social de las personas emprendedoras. Incluso, tiene el mérito de ofrecernos un concepto o definición legal de responsabilidad social ${ }^{8}$. Sin embargo, quizá convenga advertir, que el significado y las exigencias de lo que se viene considerando como responsabilidad social empresarial o corporativa, parece que desborda el ámbito del emprendimiento y de los emprendedores y se instala, propiamente, en el ámbito más general de la actuación de las empresas. Así, se suele señalar que la responsabilidad social empresarial se identifica con una forma de comportamiento de las empresas destinado a corregir las externalidades negativas producidas por la pro-

7.- El artículo 16 del Estatuto de Autonomía que dispone los principios rectores de las políticas públicas, establece en su número 5, 10 siguiente: El desarrollo de todas las formas de actividad empresarial, con especial atención a la pequeña y mediana empresa y a los emprendedores autónomos, y el fomento de las iniciativas de la economía social, especialmente al cooperativismo y su promoción.

8.- Artículo 7. Emprendedores éticos y socialmente responsables. La Administración de la Comunidad de Castilla y León fomentará la responsabilidad social de las personas emprendedoras. Se entenderá por tal la integración voluntaria en el gobierno y gestión de sus empresas, más allá del cumplimiento estricto de las obligaciones legales vigentes, de las preocupaciones sociales, laborales, medioambientales y de respeto a los derechos humanos y a la igualdad de oportunidades entre mujeres y hombres, que surgen de la relación y el diálogo con sus grupos de interés, introduciendo compromisos éticos en su gestión y responsabilizándose así de las consecuencias y los impactos que se derivan de sus acciones. 
pia actividad empresarial a través de acciones dirigidas a conservar y mejorar el entorno social y medioambiental en el que actúan (Burillo y Navarro, 2014: 81). De manera más concreta algunos autores han podido definir a la responsabilidad social empresarial como el conjunto de obligaciones -se habla, incluso, de obligaciones legales y éticas- de la empresa que surgen de la relación con sus grupos de interés y del desarrollo de su actividad de la que se derivan impactos en el ámbito social, medioambiental, laboral y de derechos humanos en un contexto global ${ }^{9}$. El Foro de expertos sobre responsabilidad social de la empresa, en 2007, consideró que, además del cumplimiento estricto de las obligaciones legales vigentes, la responsabilidad empresarial o corporativa es la integración voluntaria en su gobierno y gestión, en su estrategia, políticas y procedimientos, de las preocupaciones sociales, laborales, medioambientales y de respeto a los derecho humanos que surgen de la relación y el diálogo transparentes con su grupos de interés, responsabilizándose así de las consecuencias y los impactos que se derivan de sus acciones ${ }^{10}$.

Convendrá, pues, tener presente la caracterización de esa responsabilidad social empresarial para no caer en la tentación de confundir el fin social, que, desde luego, habrá de estar presente en cualquier emprendimiento social, de la responsabilidad social empresarial, que podrá o no estar presente en cualquier tipo de empresa. Y ello porque, hoy por hoy, esa responsabilidad social está caracterizada por la nota de la asunción voluntaria que, incluso, a veces, se ha visto para las "sociedades tradicionales como un complemento para el objetivo de la maximización de beneficio de sus accionistas o propietarios a través de estrategias sociales y/o ambientales" (Burillo y Navarro, 2014: 82).

\section{b) Eliminar o reducir trabas y trámites administrativos para facilitar la creación de empre- sas (Título III)}

Anticipamos ya que los trámites administrativos no son motivo determinante del desarrollo de la iniciativa emprendedora. El legislador de Castilla y León no parece ajeno a esa moda -a veces parece una obsesión- de las Administraciones públicas con la rapidez y las cifras estadísticas. Con todo, se adoptan algunas medidas necesarias. Se promueve la implantación de la autorización o licencia provisional, con la declaración responsable del promotor; se reducen los plazos; se potencian la teletramitación y la simplificación documental; la mejora de la calidad normativa, etc.

\section{c) Medidas de apoyo al emprendedor (Título IV)}

Se articula el denominado Sistema Integral de Apoyo al Emprendedor (SIAE), que se configura como un mecanismo de coordinación de todos los servicios de asesoramiento, información y apoyo.

9.- Vid. Burillo y Navarro, 2014: 81-82, tomando la definición de Vázquez Oteo, O.: "Responsabilidad social empresarial: matices conceptuales, Lan Harremanak, núm. 14, 2006, p. 16.

10.- Vid. Alfonso, R. (2012): "La responsabilidad social en las entidades público-privadas", en El gobierno y la gestión de las entidades no lucrativas público-privadas, José Miguel Embid Irujo y Alberto Emparanza Sobejano (Dirs.), Marcial Pons, Madrid, 2012, pp.248-249, donde, además, se recoge una tabla temporal con las distintas definiciones de Responsabilidad Social corporativa ofrecidas por distintos autores y colectivos. 
Facilitando la elaboración de planes de negocio; la figura del agente de acompañamiento o tutor del proyecto; el proporcionar espacio físico, los viveros e incubadoras; las bases de datos de buenas prácticas; la creación de una comunidad digital de personas emprendedoras; el apoyo a la producción 0 a la comercialización (redes de contacto; mentorización; acompañamiento) y a la financiación pública (p. e. sociedades públicas de capital riesgo o inversión) y privada (redes de inversores; financiación alternativa).

\section{d) Coordinación de políticas y servicios de apoyo a las personas emprendedoras: Elaboración de un Plan de Apoyo (Título V)}

Como antes anticipamos, el Consejo de Gobierno de la Junta de Castilla y León aprobó el 10 abril de 2014 el I Plan de Apoyo a la Creación de Empresas (ACUERDO 34/2014, de 10 de abril, de la Junta de Castilla y León, BOCyL del 14, por el que se aprueba el I Plan de Apoyo a la Creación de Empresas en Castilla y León). En él encontramos dos actuaciones en materia de economía social.

Por un lado, en el ámbito del llamado Proyecto ADE rural (Medida IV.1.3. Emprendimiento rural ( $A D E$ rural), dentro de las actuaciones a realizar, se contempla, en primer lugar, el desarrollo de un plan de actuación para cada comarca, con lo que se puede atender a las peculiaridades de cada una de ellas. También se prevén programas de difusión, formación, promoción y refuerzo de las fórmulas de cooperativismo y de economía social, así como la información sobre las potencialidades para la creación de empresas, (especialmente cooperativas y de economía social), además de promover la integración de las cooperativas existentes en cooperativas de segundo grado o en "plataformas" de comercialización o suministro para sus asociados.

Por otro lado, como objetivos de medidas de apoyo a la creación de empleo (Medida IV.4.10), se indican las de impulsar la creación de empleo autónomo, aumentar las tasas de actividad y de ocupación, y discriminar positivamente a colectivos con especial dificultad de acceso y/o integración en el mundo laboral o empresarial. Entre las actuaciones concretas a realizar se indican las siguientes: capitalización de la prestación por desempleo; establecimiento como autónomos de personas desempleadas; creación y consolidación de cooperativas y sociedades laborales; creación y mantenimiento de centros especiales de empleo; creación y mantenimiento de empresas de inserción; creación de empresas por mujeres en el ámbito rural; contratación del primer trabajador por parte de empresarios autónomos.

En fin, la Ley prevé, también, la celebración de un Foro Regional de Apoyo a la Creación de Empresas, como medio de participación de todas instituciones y empresas adheridas al SIAE; así como la coordinación de infraestructuras para el desarrollo de proyectos empresariales (viveros; incubadoras; parques empresariales; parques científicos y tecnológicos). 


\section{6.- Conclusiones}

El emprendimiento es un término poliédrico que lleva implícito un dinamismo, una generación de ideas, una búsqueda de efectos beneficiosos sobre el conjunto de la economía y de la sociedad. Es cierto, sin embargo, que en las iniciativas legislativas de impulso, reconocimiento o apoyo a los emprendedores que se han dado en los últimos tiempos en nuestro país, predomina un concepto de emprendedor que en poco o nada se diferencia del concepto de empresario tradicionalmente asentado en el campo del derecho de la empresa. A lo sumo, se incluye en la consideración de emprendedor a los que desarrollan actividades profesionales (particularmente, profesionales liberales). Esto ha motivado no pocas reticencias, particularmente en la literatura jurídica mercantil, a la incorporación del concepto de emprendedor como destinatario de las normas reguladoras de la actividad económica en el mercado, dada su confusa delimitación.

El concepto de emprendedor, en nuestra opinión, no viene a remplaza ni sustituir a conceptos tradicionalmente asentados en el ordenamiento jurídico como el del empresario. Probablemente, como se ha dicho, ese concepto de emprendedor en el campo del Derecho mercantil esté simplemente de paso (Peinado y Roncero, 2014:2). Probablemente, también, en el Derecho mercantil, terminen asentándose otros conceptos más útiles para la delimitación de su ámbito de aplicación, como el de operador económico, que propone el Proyecto de Código mercantil. Sin embargo, no puede desconocerse que, desde el punto de vista teórico, los conceptos de emprendedor o de iniciativa emprendedora superan y difieren, de algún modo, los conceptos de empresario y de iniciativa empresarial. En los últimos años, especialmente, la literatura de la empresa ha venido trabajando en los efectos de la orientación emprendedora en el desempeño empresarial. Y si la literatura económica reconoce y propone un trato y características diferentes para los emprendedores, la ciencia jurídica, que no puede dejar sin respuesta a los conflictos de intereses que se plantean, debería propiciar también la pertinente configuración institucional de la figura.

La configuración teórica de la acción emprendedora, puede abordarse no solo desde la perspectiva de los exclusivos intereses de la empresa sino teniendo en cuanta, también, otros objetivos e intereses que trascienden a los de la propia empresa. Por ello, doctrinalmente, al menos, pueden distinguirse un emprendimiento empresarial o emprendimiento de negocio; un emprendimiento social, cuyo protagonismo corresponde a las empresas sociales y a las entidades de economía social, además de un emprendimiento público, que corresponderá a las Administraciones Públicas.

El emprendimiento social, que es el que constituye el objeto de nuestro trabajo, propone dar respuesta a necesidades sociales, promueve y sostiene valores sociales; poniendo sus conocimientos, capacidades y recursos al servicio de la sociedad, y puede ser tratado como una variante del empren- 
dimiento, en el que el emprendedor -sea persona física o jurídica- identifica, promueve o facilita una actuación económica, innovadora y creativa, para la satisfacción de una necesidad social.

Por ello, entendemos nosotros, que el reconocimiento jurídico explícito de la economía social y de sus agentes, que se hace en la Ley española de 5/2011, de 29 de marzo, de Economía social, puede propiciar que el emprendimiento se canalice bajo las formas jurídicas de las entidades de economía social que esa Ley reconoce o permite reconocer (cooperativas, mutualidades, fundaciones, asociaciones, sociedades laborales, empresas de inserción, centros especiales de empleo, cofradías de pescadores, sociedades agrarias de transformación, entidades singulares que se creen y entidades que se incluyan en el catálogo del actual Ministerio de Empleo y Seguridad Social).

Los últimos años hemos visto distintas iniciativas de los Gobiernos y de las Administraciones públicas que, al menos programáticamente, buscan el impulso, reconocimiento o apoyo al emprendimiento. La literatura científica nos confirma que los tres factores clave para potenciar la iniciativa emprendedora son la cultura, la educación y la financiación. Los trámites administrativos para la constitución de la empresa no son un factor clave en el emprendimiento. En general, los especialistas señalan como principales obstáculos para la actividad emprendedora en España, el apoyo financiero, las políticas gubernamentales, las normas sociales y culturales y el clima económico. Sin embargo, las reformas legislativas (estatales y autonómicas) dirigidas al apoyo del emprendimiento inciden en los factores culturales, educativos y en los trámites administrativos, pero poco, o no lo suficiente, en la Financiación, cuando ésta resulta ser el factor fundamental en contextos como los actuales.

En el ámbito estatal, la más significativa es la Ley 14/2013, de 27 de septiembre, de apoyo a los emprendedores y su internacionalización. La Ley no tuvo una buena acogida entre la doctrina científica y tampoco está dando los resultados esperados. Pero, en nuestra opinión, tiene el mérito de ofrecernos la oportunidad de repensar el valor de la cultura emprendedora y, aunque sea por su omisión, del valor del emprendimiento social y la necesidad de su fomento.

También las instituciones públicas de ámbito autonómico han propiciado actuaciones orientadas al desarrollo del emprendimiento. Entre ellas, la Ley de Castilla y León 5/2013, de 19 de junio, de Estímulo a la creación de empresas en Castilla y León, constituye, pensamos nosotros, un ejemplo de la situación normativa -ciertamente escasa- del emprendimiento social en el ámbito autonómico de nuestro país. Además, la Ley autonómica proporciona actuaciones y herramientas utilices para la cultura, fomento y desarrollo de la iniciativa emprendedora. Esa Ley que, ciertamente, cuenta con una buena construcción técnico-jurídica y que tiene el mérito de reconocer expresamente como destinatarios de la norma a las entidades de economía social, carece, sin embargo, de la oportuna memoria económica que pudiera hacer creíble la puesta en marcha de todas las actuaciones en ella previstas. 
En fin, la realidad evidencia que, en las situaciones de crisis económica, son las entidades de economía social las que mayor empeño ponen en combatir los graves efectos que la crisis produce, particularmente, en los sectores más desfavorecidos, ello justifica y reclama la necesidad del reconocimiento normativo expreso y el apoyo institucional a las empresas y entidades de economía social.

\section{7.- Bibliografía}

ALEMANY, L., ALVAREZ, C., PLANELLAS, M. \& URBANO, D. (2011): Libro Blanco de la Iniciativa Emprendedora en España, Fundación Príncipe de Girona, Barcelona.

ALFARO AGUILA REAL, J. (2013): "La bazofia se aproxima al BOE", Blog Derecho Mercantil http://derechomercantilespana.blogspot.com.es/2013/08/la-bazofia-se-aproxima-al-boe.html

ALFONSO, R. (2012): "La responsabilidad social en las entidades público-privadas". En: José Miguel Embid Irujo y Alberto Emparanza Sobejano (Dirs.), El gobierno y la gestión de las entidades no lucrativas público-privadas, Marcial Pons, Madrid, 215-277.

BURILLO SÁNCHEZ, F.J. \& NAVARRO MATAMOROS, L. (2014): "La empresa social”. En: Maa del Mar Andreu Martí (Dir. y Coord.), La empresa social y su organización jurídica, Marcial Pons, Madrid, 69-90.

CAMPOS CLIMENT, V. (2010): "El emprendedor social como mecanismo de inserción sociolaboral a través de la creación de empresas de la Economía Social". En: Joan Ramon Sanchis Palacio (Dir.), Emprendimiento, economía social y empleo, IUDESCOOP, Instituto Universitario de Economía Social y Cooperativa de la Universidad de Valencia, 11-32.

CEPES, (2014): "Servicios públicos autonómicos de apoyo a los emprendedores", 27/03/2014 http://www.observatorioeconomiasocial.es/media/archivos2012/Senvicios_autonomicos_apoyo_emprend edores.pdf.

CHAVES GARCÍA, J.R. (2013): “La nueva Ley 14/2013 de Emprendedores: ¿ruido y nueces?”, Blog Contencioso, http://contencioso.es/2013/09/30/la-nueva-ley-142013-de-emprendedores-ruido-ynueces/

CONSEJO ECONÓMICO Y SOCIAL (2013): "Dictamen sobre el Anteproyecto de ley de apoyo a los emprendedores y su internacionalización", 10 de junio de 2013 http://www.ces.es/documents/10180/631510/Dic062013.pdf?version=1.0 
CONTRERAS COMECHE, R. \& GONZÁLEZ GARCÍA, N. (2010): "La medición del valor social y el impacto de los emprendedores sociales". En: J.R. Sanchis Palacio (Dir.), Emprendimiento, economía social y empleo, IUDESCOOP, Instituto Universitario de Economía Social y Cooperativa de la Universidad de Valencia, Valencia, 141-157.

CAZORLA GONZÁLEZ-SERRANO, L. (2013): "El desastre de la Sociedad de Responsabilidad Limitada de Formación Sucesiva", Blog Jurídico y docente de Luis Cazorla, http://luiscazorla.com/2013/11/eldesastre-de-la-sociedad-de-responsabilidad-limitada-de-formacion-sucesiva/.

ENCISO ALONSO-MUÑUMER, M. y SERRANO ACITORES, A. (2015): "Las transformaciones del Derecho ante la crisis: luces y sombras de la Ley de Emprendedores (1), La LEY mercantil, 10, Sección Empresa y empresario.

ENCISO SANTOCILDES, M., GÓMEZ URQUIJO, L. \& MUGARRA ELORRIAGA, A. (2012): "La iniciativa comunitaria en favor del emprendimiento social y su vinculación con la economía social: una aproximación a su delimitación conceptual", CIRIEC-España, Revista de Economía Pública Social y Cooperativa, 75, 55-80.

FAJARDO GARCÍA, G. (2012): "Las empresas de economía social en la Ley 5/2011, de 29 de marzo", Revista de Derecho de Sociedades, 38, 245-280.

HERNÁNDEZ PERLINES, F. (2014): "Orientación emprendedora de las cooperativas agroalimentarias con actividad con actividad exportadora", CIRIEC-España, Revista de Economía Pública Social y Cooperativa, 80, 29-55.

MARTOS GARCÍA, J.J. (2015): El nuevo régimen del emprendedor de responsabilidad limitada (ERL). Análisis mercantil y tributario, Tirant lo Blanch, Valencia.

MATEO HERNÁNDEZ, J.L. (2014): "Impacto societario de las Leyes 11/2013, de 26 de julio y 14/2013, de 27 de septiembre, de apoyo a los emprendedores", Revista de Derecho de Sociedades, 42, 321-339.

MORIANO LEÓN, J.A. (2005): El perfil psicosocial del emprendedor, Consejo Económico y Social, Madrid.

PANIAGUA ZURERA, M. (2011): Las empresas de la economía social. Más allá del comentario a la Ley 5/2011, de economía social, Marcial Pons, Madrid.

PAZ CANALEJO, N. (2012): Comentario sistemático a la Ley 5/2011, de Economía Social, Tirant lo Blanch, Valencia.

PEINADO GRACIA, J.I. \& RONCERO SÁNCHEZ, A. (2014): "La irrupción del «emprendedor» en el Derecho Mercantil", La LEY mercantil, 2, Sección editorial.

PRIEDE BERGAMINI, T., LÓPEZ-CÓZAR NAVARRO, C. \& RODRÍGUEZ LÓPEZ, Á. (2014): "Análisis del marco económico-jurídico específico para los emprendedores sociales. Un estudio comparado entre diversos países", CIRIEC-España, Revista de Economía Pública Social y Cooperativa, 80, 5-28. 
SALINAS RAMOS, F. \& OSORIO BAYTER, L. (2012): "Emprendimiento y Economía Social, oportunidades y efectos en una sociedad en transformación", CIRIEC-España, Revista de Economía Pública Social y Cooperativa, 75, 129-151.

SÁNCHEZ-CALERO GUILARTE, J. (2012): "Sobre la condición del empresario", El blog de Juan Sánchez-Calero Guilarte, 12 septiembre de 2012. http://jsanchezcalero.blogspot.com.es/2012/09/sobre-la-condicion-de-empresario.html

SÁNCHEZ PACHÓN, L.A. (2009): "La delimitación de las entidades y organizaciones de economía social en la próxima ley reguladora del sector", CIRIEC-España, Revista de Economía Pública Social y Cooperativa, 66, 61-84.

SÁNCHEZ PACHÓN, L.A. (2010): "El reconocimiento de la economía social y de sus agentes en el proyecto de Ley de Economía Social", Noticias de la Economía Pública Social y Cooperativa, 54, 53-58.

SANCHIS PALACIO, J.R. (Dir.) (2010): "Presentación". En: Emprendimiento, economía social y empleo, IUDESCOOP, Instituto Universitario de Economía Social y Cooperativa de la Universidad de Valencia, Valencia, 5-10.

VÁZQUEZ OTEO, O. (2006): "Responsabilidad social empresarial: matices conceptuales, Lan Harremanak, 14, 13-24. 